\title{
Ohmic Contact Mechanism for Ni/C-Faced 4H-n-SiC Substrate
}

\author{
Seongjun Kim, ${ }_{1}$ Hong-Ki Kim, ${ }^{1}$ Minwho Lim, ${ }^{2}$ Seonghoon Jeong, ${ }^{3}$ Min-Jae Kang, ${ }^{1}$ \\ Min-Sik Kang, ${ }^{1}$ Nam-Suk Lee, ${ }^{1}$ Tran Viet Cuong $\mathbb{D},{ }^{4}$ Hyunsoo Kim, ${ }^{3}$ Tobias Erlbacher, ${ }^{2}$ \\ Anton Bauer, ${ }^{2}$ and Hoon-Kyu Shin ${ }^{1}{ }^{1}$ \\ ${ }^{1}$ National Institute for Nanomaterials Technology, Pohang University of Science and Technology, Cheongam-Ro 77, \\ 37673 Pohang, Republic of Korea \\ ${ }^{2}$ Fraunhofer Institute for Integrated Systems and Device Technology, Schottkystrasse 10, 91058 Erlangen, Germany \\ ${ }^{3}$ Department of Semiconductor and Chemical Engineering, Chonbuk National University, Baekje-daero 567, \\ 54896 Jeonju, Republic of Korea \\ ${ }^{4}$ NTT Hi-Tech Institute, Nguyen Tat Thanh University, A Nguyen Tat Thanh Street, 298-300 Ho Chi Minh City, Vietnam
}

Correspondence should be addressed to Hoon-Kyu Shin; shinhk@postech.ac.kr

Received 17 July 2019; Revised 11 October 2019; Accepted 17 October 2019; Published 5 December 2019

Guest Editor: Francesca A. Scaramuzzo

Copyright (C) 2019 Seongjun Kim et al. This is an open access article distributed under the Creative Commons Attribution License, which permits unrestricted use, distribution, and reproduction in any medium, provided the original work is properly cited.

In this work, the ohmic contact mechanism of $\mathrm{Ni}$ electrodes on $\mathrm{C}$-faced $4 \mathrm{H}-n$-SiC was investigated by evaluating the electrical and microstructural properties in the contact interface as a function of annealing temperatures ranging from 950 to $1100^{\circ} \mathrm{C}$. We determined that Ni-silicide, especially the NiSi phase, plays a key role in the formation of ohmic contacts rather than an increase in carbon vacancies in the $\mathrm{C}$-faced $\mathrm{SiC}$ substrate. A vertically oriented NiSi phase was observed in the thermally annealed sample at the optimized temperature that behaves as a current path. A further increase in annealing temperature leads to the degradation of ohmic behavior due to the formation of horizontal-type NiSi in the Ni-rich Ni-silicide/NiSi/SiC structure.

\section{Introduction}

Many technical challenges need to be overcome to improve the performance of $4 \mathrm{H}-\mathrm{SiC}$-based power devices, such as Schottky barrier diodes (SBDs) and metal-oxidesemiconductor field-effect transistors (MOSFETs). One of them is the reproducible formation of low resistance ohmic contacts. Nickel metallization, which has the lowest specific contact resistance $\left(\rho_{\mathrm{sc}}\right)$, has been frequently used for this purpose [1-8]. For example, $\rho_{\text {sc }}$ on Ni contacts to Si-faced $4 \mathrm{H}-\mathrm{n}$ SiC epitaxial layer is between $2.8 \times 10^{-3}$ and $1.1 \times 10^{-6} \Omega \cdot \mathrm{cm}^{2}$ under the high temperature annealing at $\sim 1000^{\circ} \mathrm{C}$, depending on the process technique and doping concentration [2, 6-8]. The thermal annealing at high temperature, however, can damage the oxide and $\mathrm{SiC} / \mathrm{SiO}_{2}$ interface, which is undesirable for device fabrication. In that sense, Ni-based metal structures have been also studied in order to form the low resistance ohmic contact even under the low temperature annealing process. With low annealing temperature at $750^{\circ} \mathrm{C}$ or $950^{\circ} \mathrm{C}$, the ohmic contacts have low $\rho_{\text {sc }}$ values, respectively, of $8 \times 10^{-4}$ and $4.2 \times 10^{-5} \Omega \cdot \mathrm{cm}^{2}$ and were achieved by using $\mathrm{Ni} / \mathrm{Ti} / \mathrm{Al}$ and $\mathrm{Ni} / \mathrm{Ti} / \mathrm{Al} / \mathrm{W}$ metal schemes [9, 10].

The development of ohmic contact can be possible based on the sufficient understanding of the formation mechanisms of $\mathrm{Ni}$ contact on $\mathrm{Si}$-faced $4 \mathrm{H}-\mathrm{n}-\mathrm{SiC}$. In the case of $\mathrm{Si}$-faced $4 \mathrm{H}-\mathrm{n}-\mathrm{SiC}$, carbon accumulation at the interface and donorlike carbon vacancies $\left(V_{\mathrm{C}}\right)$ that can lower the barrier height $\left(\Phi_{\mathrm{B}}\right)$ and reduce $\rho_{\mathrm{sC}}$ have been suggested as a possible mechanism for ohmic contact formation [2-5]. In addition, the formation of $\mathrm{Ni}$-silicide by thermal treatment may play a predominant role in the formation of ohmic contacts [5-8]. Indeed, it is highly desirable to optimize the ohmic contact on the SiC substrate, particularly on $\mathrm{C}$-faced $4 \mathrm{H}-\mathrm{SiC}$ for vertical device structures. However, the mechanism for ohmic contact formation in $\mathrm{C}$-faced $4 \mathrm{H}-\mathrm{n}-\mathrm{SiC}$ has not yet been completely elucidated.

In this study, we investigated the ohmic contact mechanism on $\mathrm{Ni} / 4 \mathrm{H}-\mathrm{n}-\mathrm{SiC}$ substrate (C-faced) interfaces. The electrical properties of contacts were evaluated using the 


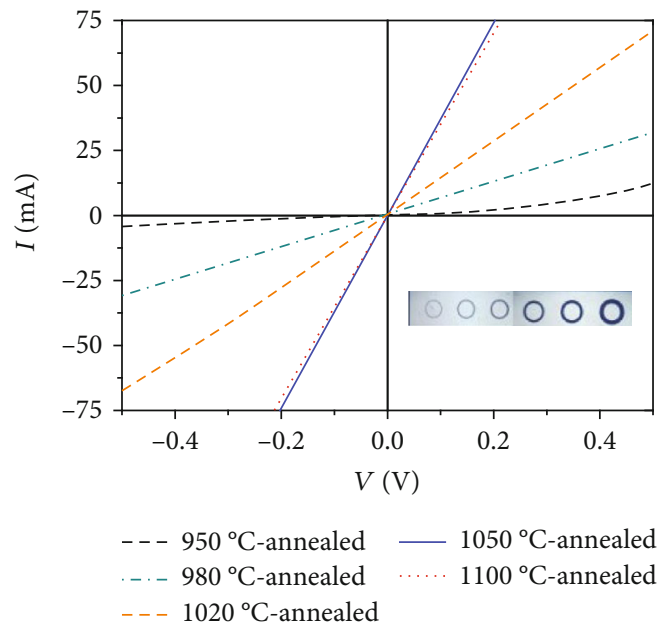

(a)



(b)

FIgURE 1: (a) $I-V$ characteristics of $\mathrm{Ni} / \mathrm{n}$-SiC substrate contacts as a function of annealing temperature $(d=5 \mu \mathrm{m})$. (b) $I-V$ curves of $1050^{\circ} \mathrm{C}$-annealed sample as a function of $d$. The inset shows the total resistance $R_{\mathrm{T}}-d$ plot.

transmission line model (TLM). The formation and degradation mechanisms of ohmic contacts with the annealing process were investigated by current-voltage-temperature $(I-V-T)$ measurements, scanning transmission electron microscopy (STEM), and energy-dispersive X-ray spectroscopy (EDS).

\section{Experimental Methods}

For this study, we use commercially available $4^{\circ}$ off-axis n-type $4 \mathrm{H}-\mathrm{SiC}$ substrates with a resistivity of $0.02 \Omega \cdot \mathrm{cm}$ from Cree, USA. Hall-effect measurements were performed for five SiC substrate samples using the van der Pauw method and yielded an average electron carrier concentration $(N)$ of $3.28 \times 10^{18} \pm 6.14 \times 10^{14} \mathrm{~cm}^{-3}$ and a Hall mobility $(\mu)$ of $90.8 \pm 0.12 \mathrm{~cm}^{2} / \mathrm{V} \cdot \mathrm{s}$. Prior to metal deposition, the samples were cleaned with $\mathrm{H}_{2} \mathrm{SO}_{4}: \mathrm{H}_{2} \mathrm{O}_{2}=3: 1, \mathrm{NH}_{4} \mathrm{OH}$ :$\mathrm{H}_{2} \mathrm{O}_{2}: \mathrm{H}_{2} \mathrm{O}=1: 1: 5$, and buffered oxide etchant solutions for 10,10 , and $1 \mathrm{~min}$, respectively.

To investigate the ohmic contacts on C-faced $4 \mathrm{H}-\mathrm{SiC}$, namely, the backside of the SiC substrate, TLM patterns with circular geometry (diameter of the inner circle was $200 \mu \mathrm{m}$, and the distance between inner and outer circles was $d=5$, $10,15,25,35$, and $50 \mu \mathrm{m}$ ) were defined using photolithography, as shown in the inset of Figure 1(a). As a contact metal, $150 \mathrm{~nm}$ thick Ni was deposited on the patterned $\mathrm{SiC}$ substrate using an $e$-beam evaporator. After the lift-off process, rapidthermal annealing (RTA) was performed at 950, 980, 1020, 1050 , and $1100^{\circ} \mathrm{C}$ for $1 \mathrm{~min}$ in $\mathrm{N}_{2}$ ambient in order to stimulate a reaction between $\mathrm{Ni}$ and the $4 \mathrm{H}-\mathrm{SiC}$ substrate. All electrical characteristics of the contacts were evaluated in a vacuum chamber $(<0.02$ Torr $)$ equipped with a variabletemperature chuck system using a parameter analyzer (HP 4156A). I-V-T measurements were performed to characterize the contact properties in the temperature range of $300-420 \mathrm{~K}$. STEM and EDS were also performed to investigate the structural properties of the contacts using a JEOL JEM-2100F.

\section{Results and Discussion}

Figure 1(a) shows the $I-V$ characteristics of Ni contacted to the bottom of the n-type SiC substrate as a function of annealing temperature. The current and voltage were measured from adjacent TLM pads with a $d$ of $5 \mu \mathrm{m}$. It is shown that the $I-V$ curves are significantly dependent on the annealing temperature. For example, the $I-V$ curve of the $950^{\circ} \mathrm{C}$-annealed sample exhibited a rectifying characteristic; however, the $I-V$ curves of samples annealed at temperatures equal to and higher than $980^{\circ} \mathrm{C}$ were linear indicating the formation of ohmic contacts. Using the TLM method [11], the $1050^{\circ} \mathrm{C}$-annealed sample was computed to have the lowest $\rho_{\mathrm{sc}}\left(5.67 \times 10^{-4} \Omega \cdot \mathrm{cm}^{2}\right)$ and sheet resistance $\left(R_{\mathrm{sh}}\right)$ of $13.6 \Omega / \mathrm{sq}$ (Figure 1(b)). Note that $\rho_{\mathrm{sc}}$ for $1020^{\circ} \mathrm{C}$-annealed sample $\left(9.63 \times 10^{-4} \Omega \cdot \mathrm{cm}^{2}\right)$ is higher than that of the $1050^{\circ} \mathrm{C}$-annealed sample, and the reliable contact parameters for $980^{\circ} \mathrm{C}$-annealed sample could not be obtained due to the nonlinear relation between the total resistance $\left(R_{\mathrm{T}}\right)$ and $d$ (not shown here). Thus, $1050^{\circ} \mathrm{C}$ was determined as the most optimized annealing temperature. One interesting result was that thermal annealing at only $1100^{\circ} \mathrm{C}$ led to a decrease in current values at the relevant voltages and an increase in $\rho_{\mathrm{sc}}\left(8.0 \times 10^{-4} \Omega \cdot \mathrm{cm}^{2}\right)$. A possible explanation for degradation of electrical properties is discussed in more detail in the last section.

Prior to this work, it was unclear whether the Ni-silicide formed at the contact interface or the out-diffusion of $\mathrm{C}$ atoms played a key role in the formation of ohmic contacts when $\mathrm{Ni}$ was deposited as an ohmic metal on n-type $\mathrm{SiC}$ [2-8]. According to previous studies [2-5], the outdiffusion of carbon leads to $V_{\mathrm{C}}$, which acts as a donor, causing an increase of $N$ underneath the contact interface. Therefore, if an out-diffusion of carbon was critical to the formation of ohmic contacts, both the increase of $N$ and decrease of $\Phi_{\mathrm{B}}$ should be observed simultaneously [2]. To investigate if the origin of ohmic contact formation was 


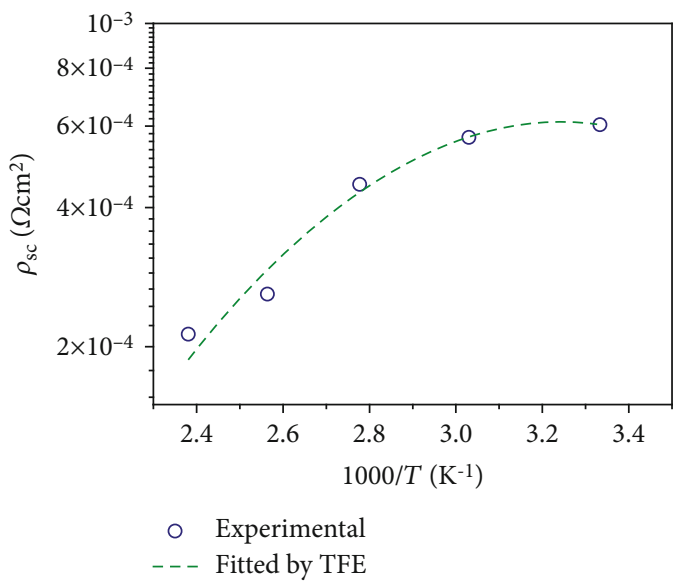

Figure 2: $\rho_{\text {sc }}$ vs. $1000 / T$ plot for a $1050^{\circ} \mathrm{C}$-annealed sample.

dominated by the increase of $N$ due to an out-diffusion of carbon atoms in the contact interface on C-faced $4 \mathrm{H}-\mathrm{n}-\mathrm{SiC}$, $\rho_{\text {sc }}$ values for the $1050^{\circ} \mathrm{C}$-annealed sample were plotted as a function of annealing temperature (Figure 2). The thermionic field emission (TFE) model [11] was used to calculate $\rho_{\text {sc }}$ since the $N$ value predicts that the TFE model would provide a good approximation, i.e., TFE dominates when $0.5<E_{00} / k T<5$. Here, $E_{00}$ is given by $E_{00}=(q h / 4 \pi)$ $\left(N / \varepsilon_{s} m^{*}\right)^{1 / 2}$, where $m^{*}$ is the electron effective mass $\left(m^{*}=0.36 m_{\mathrm{e}}\right)$ and $\varepsilon_{s}$ is the dielectric constant of $4 \mathrm{H}-\mathrm{SiC}$ $\left(\varepsilon_{s}=9.66\right)$ [5]. With $N=3.28 \times 10^{18} \mathrm{~cm}^{-3}$ and $T=300 \mathrm{~K}$, the calculation shows that $E_{00} / k T$ was as low as 0.695 which lies in the TFE regime [11]. $\rho_{\mathrm{sc}}$ was calculated using

$\rho_{\mathrm{sc}}=\frac{\operatorname{coth}^{1 / 2}\left(E_{00} / k T\right) \cosh \left(E_{00} / k T\right)}{\left(q A^{* *} / k^{2}\right)} \exp \left(\frac{q\left(\Phi_{\mathrm{B}}+V_{n}\right)}{E_{00} \operatorname{coth}\left(E_{00} / k T\right)}-\frac{q V_{n}}{k T}\right)$,

where $A^{* *}$ is the Richardson constant $\left(146 \mathrm{~A} / \mathrm{cm}^{2} \mathrm{~K}^{2}\right)$ [5] and $V_{n}$ is the energy difference between the conduction band edge $\left(E_{\mathrm{c}}\right)$ and the Fermi level $\left(E_{\mathrm{F}}\right)$. From the successful theoretical fit of experimental data using Equation (1) as shown in the broken line of Figure $2, \Phi_{\mathrm{B}}$ of $0.62 \mathrm{eV}, E_{00}$ of $0.019 \mathrm{eV}$, and $N$ of $3.7 \times 10^{18} \mathrm{~cm}^{-3}$ were obtained. Note that $\Phi_{\mathrm{B}}$ was lower than the theoretically expected value $\left(\Phi_{\mathrm{B}}=\Phi_{\mathrm{Ni}}(5.15 \mathrm{eV})-\chi_{4 \mathrm{H}-\mathrm{SiC}}(3.6 \mathrm{eV})=1.55 \mathrm{eV}\right)[12]$, whereas $N$ evaluated by the TFE model was nearly constant compared to the value determined by Hall-effect measurement. Therefore, the above results suggest that a more dominant factor other than the generation of $V_{C}$ should be used to explain the formation of an ohmic contact at the $\mathrm{Ni} / \mathrm{C}$-faced $4 \mathrm{H}-\mathrm{n}-\mathrm{SiC}$ interface.

According to the literature [2-8], various Ni-silicide phases are formed at the interface of the Ni-based contacts on $4 \mathrm{H}-\mathrm{n}-\mathrm{SiC}$ during thermal annealing. For example, Ni-rich regions, typically comprised of $\mathrm{Ni}_{31} \mathrm{Si}_{12}$ and $\mathrm{Ni}_{2} \mathrm{Si}$ phases, are formed under a low annealing temperature of $600^{\circ} \mathrm{C}$. The $\mathrm{Ni}_{31} \mathrm{Si}_{12}$ hexagonal phase, which is mainly formed at a considerably low temperature, has little effect on the reduction of $\rho_{\mathrm{sc}}[5,8]$. As the annealing temperature is increased $\left(>\sim 900^{\circ} \mathrm{C}\right)$, the $\mathrm{Ni}$-silicide phases recrystallize at the contact interfaces, i.e., a full transformation of $\mathrm{Ni}_{31} \mathrm{Si}_{12}$ into the $\mathrm{Ni}_{2} \mathrm{Si}$ orthorhombic phase $[3,8]$. Several studies have shown that this $\mathrm{Ni}_{2} \mathrm{Si}$ phase plays a key role in determining the electrical transport characteristics at the contact interfaces, namely, the recrystallization into the $\mathrm{Ni}_{2} \mathrm{Si}$ phase leads to a reduction of $\rho_{\mathrm{sc}}$ and a decrease in $\Phi_{\mathrm{B}}[6,8]$. If this model is valid, both the uniform distribution of $\mathrm{Ni}$ and $\mathrm{Si}$ atoms at metallic regions and the linear increase of current with applied bias should be observed for the sample annealed at $950^{\circ} \mathrm{C}$.

To investigate the predominant ohmic mechanism in terms of structural changes, STEM and EDS measurements were performed. Figure 3 shows the STEM images and the corresponding EDS elemental mapping for the samples annealed at 950,1050 , and $1100^{\circ} \mathrm{C}$. The interface between the $\mathrm{SiC}$ substrate and contact metal is clearly distinguishable in the $950^{\circ} \mathrm{C}$-annealed sample (Figure 3(a)). Figures 3(c) and 3(d) show that $\mathrm{Si}$ and $\mathrm{C}$ atoms out-diffused toward the contact metal region and were evenly distributed, indicating a transformation into the single $\mathrm{Ni}$-silicide phase, which was expected to be $\mathrm{Ni}_{2} \mathrm{Si}$. However, the $I-V$ curve of the $950^{\circ} \mathrm{C}$-annealed sample was strongly rectifying as shown in Figure 1(a). Therefore, we can conclude that the formation of Ni-rich Ni-silicide (NNS), especially $\mathrm{Ni}_{2} \mathrm{Si}$, is not the major factor in forming ohmic contacts on C-faced n-SiC. Indeed, this result is supported by Han et al. who reported that the $\Phi_{\mathrm{B}}$ of $\mathrm{Ni}$-silicide, comprised of $\mathrm{Ni}_{2} \mathrm{Si}$, is higher than Ni metal on n-type $\mathrm{SiC}$ [2]. Interestingly, the distinct difference between the $950^{\circ} \mathrm{C}$-annealed sample and the samples with higher annealing temperatures was observed in elemental mapping images. As indicated by the superimposed white lines in Figures 3(h) and 3(l) directed by white arrows, a $\mathrm{C}$-rich region was formed after thermal annealing at $1050^{\circ} \mathrm{C}$ or more, in which the composition of Ni-silicide in this C-rich region corresponds to $\mathrm{NiSi}[2,7]$. From a thermodynamic point of view, the formation of $\mathrm{NiSi}$ is valid since the difference in Gibbs free energy for NiSi at $950^{\circ} \mathrm{C}$ is negative $\left(\Delta G_{950 \circ \mathrm{C}}=-34.4 \mathrm{~kJ} / \mathrm{mol}\right)[7,13]$. Moreover, according to previous research, the formation of the $\mathrm{NiSi} / \mathrm{SiC}$ system contributes to the significant reduction in contact resistance. Considering our and previous results mentioned above, it is likely that the formation of ohmic contacts is also related to the formation of $\mathrm{NiSi}$ phases rather than $\mathrm{Ni}_{2} \mathrm{Si}$ even in the case of $\mathrm{C}$-faced $\mathrm{SiC}$. Thus, an ohmic contact for the $\mathrm{Ni}$ metallization on C-faced $4 \mathrm{H}-\mathrm{n}-\mathrm{SiC}$ can be achieved by the formation of $\mathrm{C}$-rich areas corresponding to the NiSi phase.

It is also necessary to investigate why the ohmic properties degraded with annealing beyond the optimized temperature. One possible factor that increases $\rho_{\mathrm{sc}}$ value might be the change of the C-rich region thickness. However, the thickness of $\mathrm{C}$-rich region varies between 20 and $36 \mathrm{~nm}$ as shown in Figures 3(h) and 3(l). Therefore, the electrical properties at the contact interface have little to no correlation with the thickness of the C-rich region. Another possible explanation for ohmic contact degradation is the structural change in the C-rich area. Indeed, ohmic behavior was observed in both the $1050^{\circ} \mathrm{C}$ - and $1100^{\circ} \mathrm{C}$-annealed samples. Although C-rich 


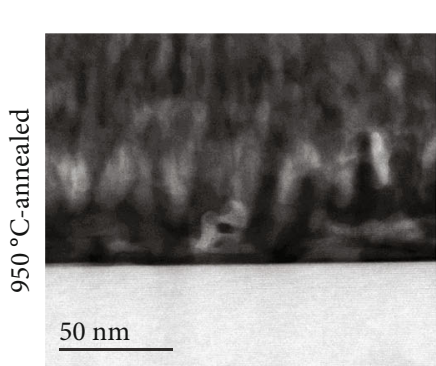

(a)



(e)

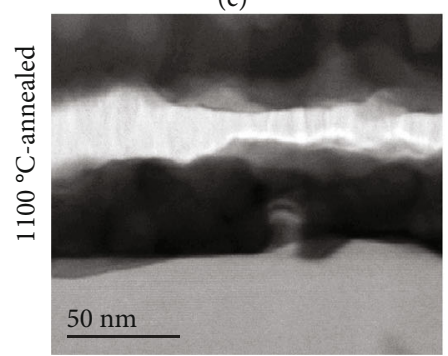

(i)

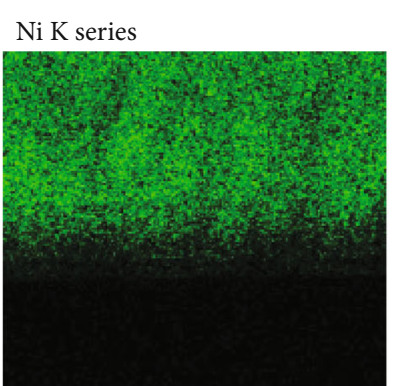

(b)

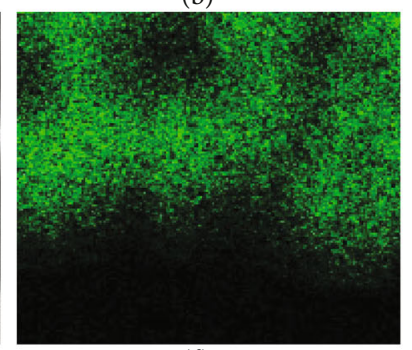

(f)

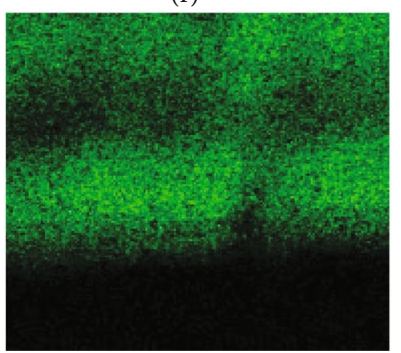

(j)

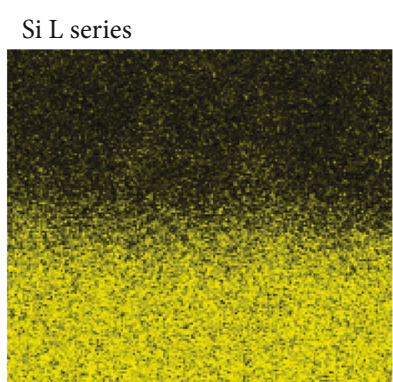

(c)



(g)

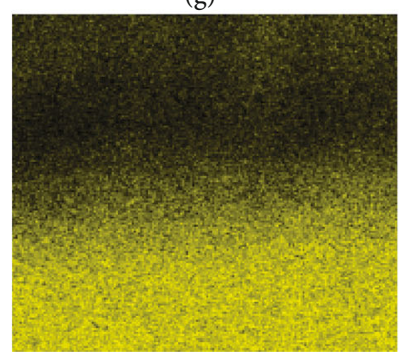

(k)

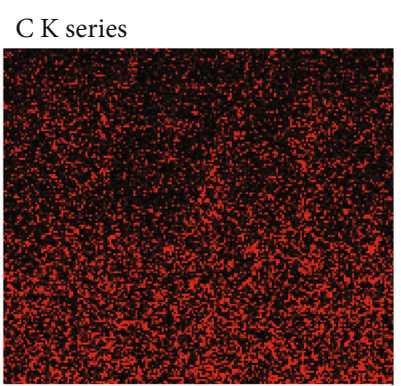

(d)

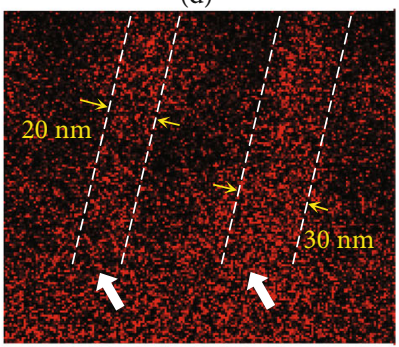

(h)

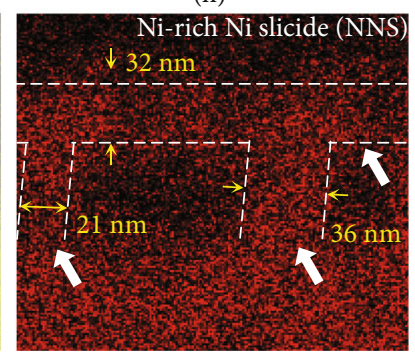

(1)

FIGURE 3: STEM and EDS elemental mapping images for (a-d) $950^{\circ} \mathrm{C}$-annealed, (e-h) $1050^{\circ} \mathrm{C}$-annealed, and (i-l) $1100^{\circ} \mathrm{C}$-annealed sample, respectively.

regions were observed in both samples, the corresponding structures were clearly formed with different shapes. For example, for samples annealed at $1050^{\circ} \mathrm{C}$, the $\mathrm{C}$-rich region was formed vertically (Figure 3(h)), indicating that the current path with low resistance between the $\mathrm{SiC}$ and the top electrode was well formed. When the annealing temperature was increased by $50^{\circ} \mathrm{C}$, i.e., in the case of $1100^{\circ} \mathrm{C}$-annealed sample, C-rich areas were formed horizontally as well as vertically, as shown in Figure 3(1). In addition, NNS was formed just above the horizontal C-rich region, i.e., a $\mathrm{Ni}_{2} \mathrm{Si}$ or a $\mathrm{Ni}_{31} \mathrm{Si}_{12} / \mathrm{NiSi} / \mathrm{SiC}$ structure was formed. As mentioned before, the formation of $\mathrm{NiSi} / \mathrm{SiC}$ structures has the effect of reducing $\rho_{\mathrm{sc}}$, compared with the $\mathrm{NNS} / \mathrm{SiC}$ system $[2,7]$. On the other hand, the formation of NNS/NiSi contacts could negatively affect the current flow. Due to the work function of NiSi $(\sim 4.5 \mathrm{eV})$ and NNS $(\sim 4.8 \mathrm{eV})[14]$, there is a contact potential difference $\left(q \Delta V=\Phi_{\mathrm{NNS}}-\Phi_{\mathrm{NiSi}}\right)$ of $0.3 \mathrm{eV}$ between the NNS/NiSi structure. Therefore, to produce the same current value for the $\mathrm{NNS} / \mathrm{NiSi} / \mathrm{SiC}$ and $\mathrm{NiSi} / \mathrm{SiC}$ structures, an additional voltage of $0.3 \mathrm{~V}$ should be applied to the former structure. Eventually, the increase in $\rho_{\text {sc }}$ of the contact annealed above the optimized temperature was due to the horizontal formation of the $\mathrm{C}$-rich region causing the $\mathrm{NNS} / \mathrm{NiSi} / 4 \mathrm{H}-\mathrm{n}-\mathrm{SiC}$ structure. Indeed, it is evident that the formation of the horizontal C-rich area restricts current flow although the exact origin of ohmic contact degradation on $\mathrm{Ni} / \mathrm{C}$-faced $4 \mathrm{H}-\mathrm{n}-\mathrm{SiC}$ should be further investigated.

\section{Conclusions}

The ohmic contact mechanism of Ni contact to C-face and $\mathrm{n}$-type $4 \mathrm{H}-\mathrm{SiC}$ can be characterized as follows:

(1) The carrier concentrations extracted from Hall-effect and $I-V-T$ measurements for the sample annealed at optimized conditions $\left(1050^{\circ} \mathrm{C}\right)$ are nearly constant. This proves that $V_{C}$, acting as donors, have little contribution to the formation of ohmic contacts

(2) The evidence for the formation of various Ni-silicide phases after thermal annealing was confirmed from EDS elemental mapping. It was shown that the $\mathrm{C}$-rich area corresponding to the $\mathrm{NiSi}$ phase plays a key role in the formation of ohmic contacts since the linear $I-V$ curve was observed only for the samples having C-rich regions, especially, vertically shaped C-rich regions

(3) The degradation of ohmic contacts by annealing at higher temperatures beyond the optimized temperature can be explained in terms of the structural 
change of the C-rich area. After annealing at the optimized temperature, the C-rich area formed vertically, acting as an electron pathway. Above the optimized temperature, the ohmic contacts degrade because a horizontal C-rich region was developed in the contact metal region, leading to an increase in contact resistance due to the formation of $\mathrm{NNS} / \mathrm{NiSi}$ contacts. However, the detailed effect of the Si-rich $\mathrm{Ni}$-silicide and the horizontal $\mathrm{C}$-rich region needs further investigation

\section{Data Availability}

The datasets generated during and/or analyzed during the current study are available from the corresponding author on reasonable request.

\section{Conflicts of Interest}

The authors declare that they have no conflicts of interest.

\section{Authors' Contributions}

Seongjun Kim and Hong-Ki Kim contributed equally to this work.

\section{Acknowledgments}

This research was supported by the GRDC Program through the National Research Foundation funded by the MSIT of Korea (NRF-2017K1A4A3013716).

\section{References}

[1] F. L. Via, F. Roccaforte, A. Makhtari, V. Raineri, P. Musumeci, and L. Calcagno, "Structural and electrical characterisation of titanium and nickel silicide contacts on silicon carbide," Microelectronic Engineering, vol. 60, no. 1-2, pp. 269-282, 2002.

[2] S. Y. Han, K. H. Kim, J. K. Kim et al., "Ohmic contact formation mechanism of $\mathrm{Ni}$ on $n$-type $4 \mathrm{H}-\mathrm{SiC}$," Applied Physics Letters, vol. 79, no. 12, pp. 1816-1818, 2001.

[3] I. P. Nikitina, K. V. Vassilevski, N. G. Wright, A. B. Horsfall, A. G. O'Neill, and C. M. Johnson, "Formation and role of graphite and nickel silicide in nickel based ohmic contacts to n-type silicon carbide," Journal of Applied Physics, vol. 97, no. 8, p. 083709, 2005.

[4] R. Kisiel, M. Guziewicz, K. Golaszewska, M. Sochacki, and W. Paszkowicz, "Mechanisms of carriers transport in Ni/n$\mathrm{SiC}, \mathrm{Ti} / \mathrm{n}-\mathrm{SiC}$ ohmic contacts," Materials Science-Poland, vol. 29, p. 233, 2011.

[5] A. V. Kuchuk, P. Boriwicz, M. Wzorek et al., "Ni-based ohmic contacts to n-type $4 \mathrm{H}-\mathrm{SiC}$ : the formation mechanism and thermal stability," Advances in Condensed Matter Physics, vol. 2016, Article ID 9273702, 26 pages, 2016.

[6] M. W. Cole, P. C. Joshi, and E. Ervin, "Fabrication and characterization of pulse laser deposited $\mathrm{Ni}_{2} \mathrm{Si}$ ohmic contacts on $n$-SiC for high power and high temperature device applications," Journal of Applied Physics, vol. 89, no. 8, pp. 4413-4416, 2001.
[7] S. Tanimoto, M. Miyabe, T. Shiiyama et al., "Toward a better understanding of Ni-based ohmic contacts on SiC," Materials Science Forum, vol. 679-680, pp. 465-468, 2011.

[8] A. V. Kuchuk, V. P. Kladko, K. Gołaszewska et al., "The formation mechanism of Ni-based ohmic contacts to $4 \mathrm{H}-\mathrm{n}-\mathrm{SiC}$," Materials Science Forum, vol. 717-720, pp. 833-836, 2012.

[9] X. F. Zhang, Y. D. Tang, H. J. Shen et al., "Study on simultaneous formation of ohmic contacts on $\mathrm{p}$ - and $n$ - type $4 \mathrm{H}-\mathrm{SiC}$ using Ni/Ti/Al ternary system," in 2014 12th IEEE International Conference on Solid-State and Integrated Circuit Technology (ICSICT), Guilin, China, 2014.

[10] Y. He, H. Lv, X. Tang et al., "Ohmic contacts simultaneously formed on n-type and p-type $4 \mathrm{H}-\mathrm{SiC}$ at low temperature," Journal of Alloys and Compounds, vol. 805, article S0925838819326234, pp. 999-1003, 2019.

[11] D. K. Schroder, Semiconductor Material and Device Characterization, John Wiley \& Sons, Hoboken, NJ, USA, 3rd edition, 2006.

[12] M. Wiets, M. Weinelt, and T. Fauster, "Electronic structure of $\mathrm{SiC}(0001)$ surfaces studied by two-photon photoemission," Physical Review B, vol. 68, article 125321, 2003.

[13] C.-S. Lim, K.-B. Shim, D.-W. Shin, and K. H. Auh, "Phase distribution and interface chemistry by solid state $\mathrm{SiC} / \mathrm{Ni}$ reaction," The Korean Journal of Ceramics, vol. 2, no. 1, p. 19, 1996.

[14] J. A. Kittl, M. A. Pawlak, A. Lauwers et al., "Work function of Ni silicide phases on $\mathrm{HfSiON}$ and $\mathrm{SiO}_{2}: \mathrm{NiSi}, \mathrm{Ni}_{2} \mathrm{Si}_{2} \mathrm{Ni}_{31} \mathrm{Si}_{12}$, and $\mathrm{Ni}_{3} \mathrm{Si}$ fully silicided gates," IEEE Electron Device Letters, vol. 27, no. 1, pp. 34-36, 2006. 


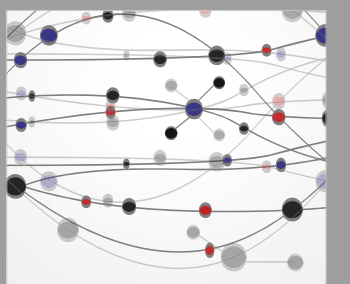

The Scientific World Journal
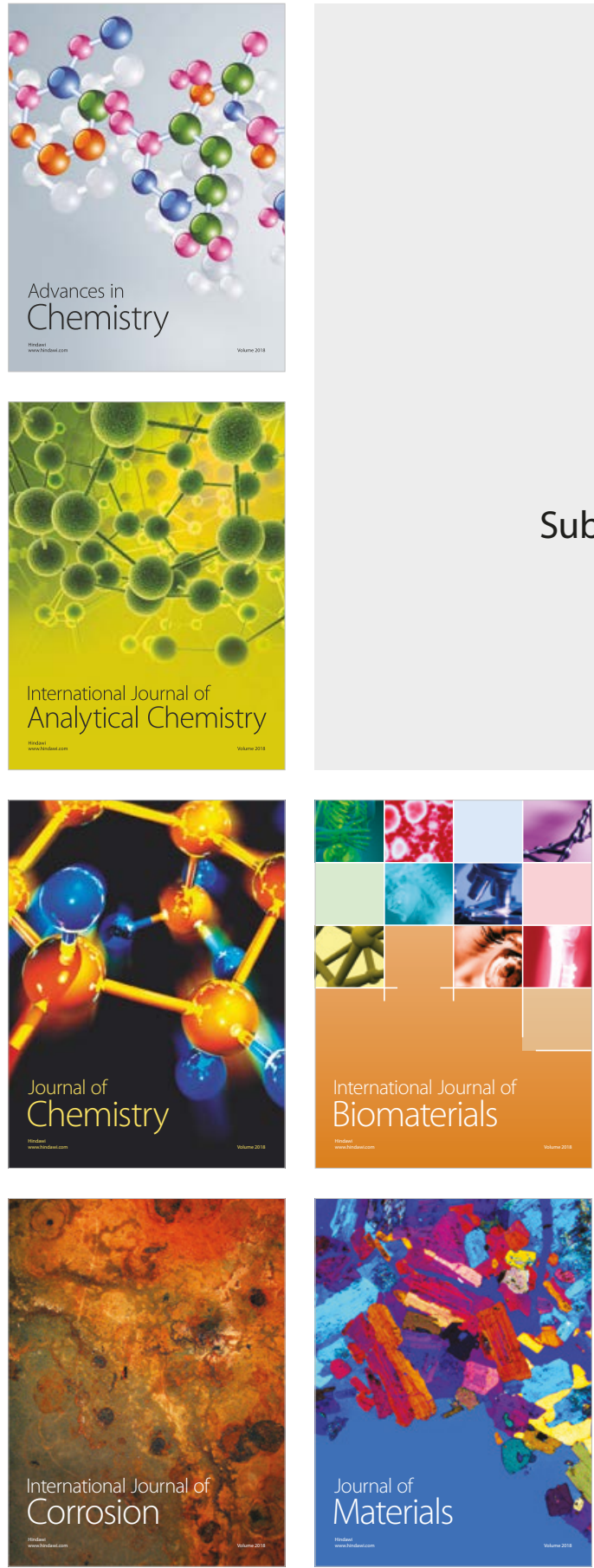

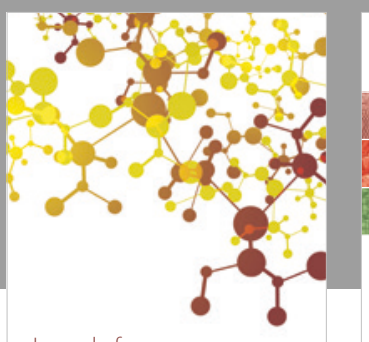

Journal of

Applied Chemistry
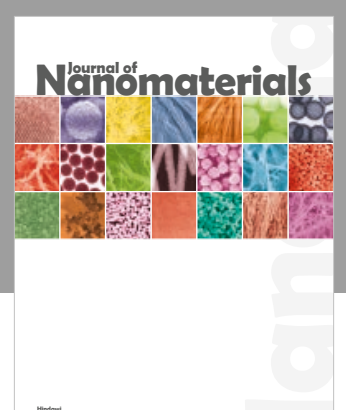

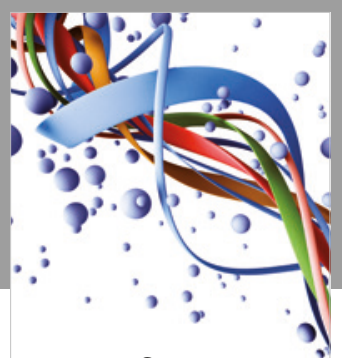

Scientifica

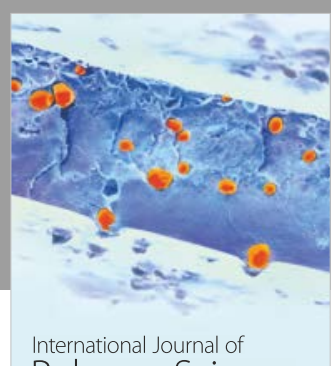

Polymer Science

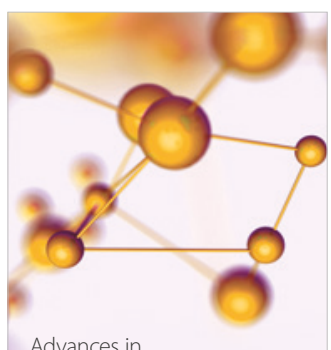

Physical Chemistry
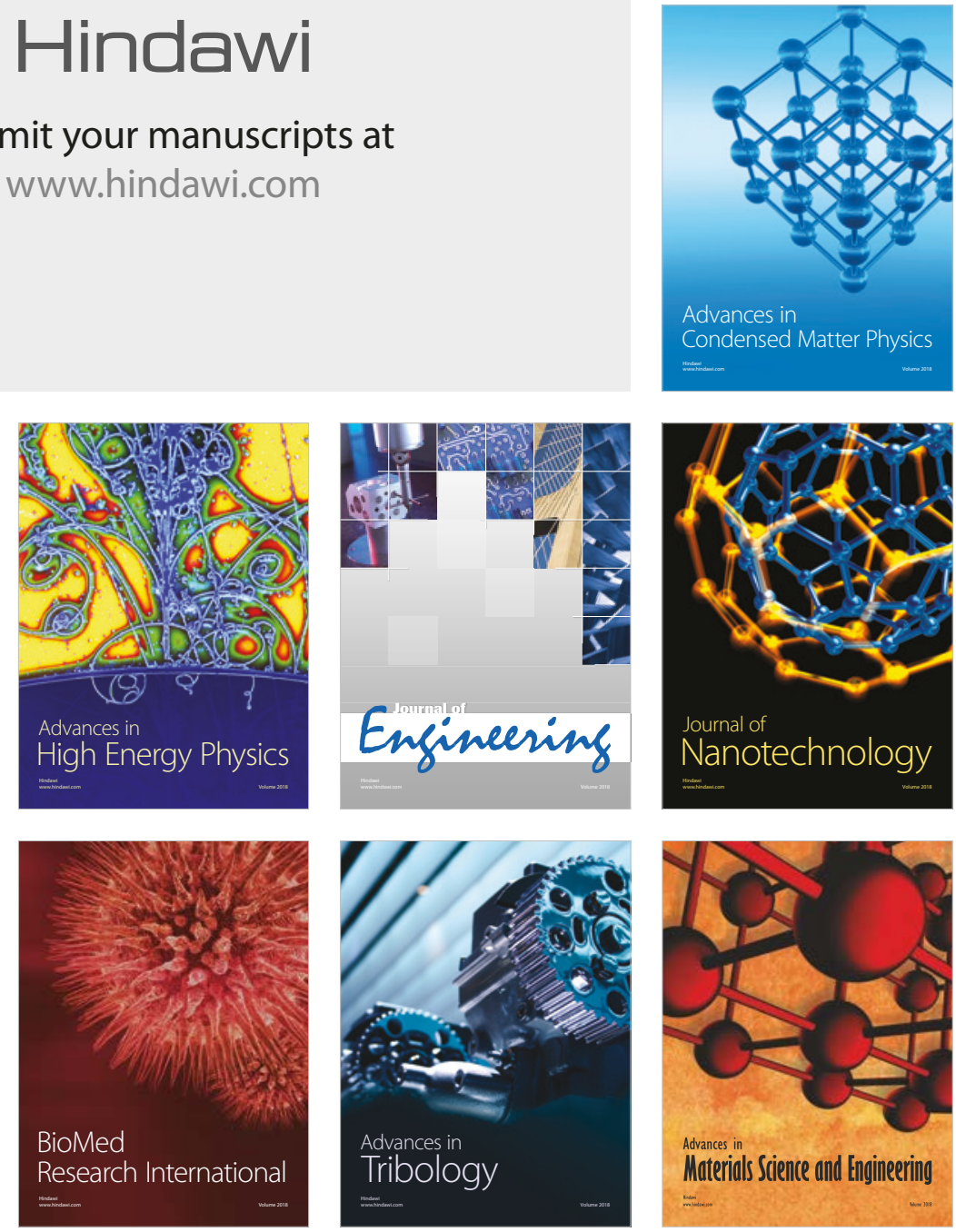